\title{
Free Space Optical Communications: Channel Modeling
}

\section{Abstract}

\author{
Maxwel V. da Silva (IC), Jaime Portugheis (PQ) e Cristhof J. R. Runge (PQ)
}

A terrestrial free space optical communication link using a commercial system was deployed across Faculty of Technology campus in Limeira. Channel measurements were collected in order to develop appropriate communication channel models. Unlike previous work, the link distance is very short (around 91 meters). Still, it was possible to observe significant scintillation index variations over a day. This behaviour agrees with previous results obtained in the literature for much longer links.

Keywords - Free space optical communications, channel measurements, scintillation index.

\section{Introduction}

Free space optical communication systems have several advantages over traditional radio frequency systems. However, optical propagation is through atmosphere and effects like absorption, scattering and turbulence are present and cause fading of received signal. Therefore, designing such systems requires models for the probability density function of the channel gain. These models depend on weather conditions of each location and are characterized by scintillation indexes (see [1] and references therein).

\section{Results and Discussion}

Chart 1 shows estimated values for scintillation index from a series of measures carried out in August, 2014. The measures of lines "Morning", "Noon" and "Night" were performed around 6:00 AM, 1:00 PM and 7:00 PM, respectively. "Temp"(Celsius), "WS"(km/h) and "W" refers to temperature, wind speed and weather, respectively.Two important facts are worth noting: a) the highest index values are those around noon. b) In the third column the index value around noon is about 10 times higher than that at the morning.

Chart 1. Estimated values for scintillation index.

\begin{tabular}{|c|l|l|l|}
\hline Morning & 0.0000147 & 0.0000252 & 0.0000202 \\
\hline Temp & 19.4 & 16.4 & 14.6 \\
\hline WS & 12.2 & 14.3 & 12.6 \\
\hline W & Cloudy & Clear & Cloudy \\
\hline Noon & 0.0000583 & 0.0002383 & 0.0002115 \\
\hline Temp & 21.0 & 25.1 & 25.5 \\
\hline WS & 15.7 & 15.1 & 12.8 \\
\hline W & Clear & Clear & Clear \\
\hline Night & 0.0000267 & 0.0000294 & 0.0000315 \\
\hline Temp & 26.8 & 14.2 & 23.7 \\
\hline WS & 12.8 & 12.1 & 15.8 \\
\hline W & Clear & Rainy & Clear \\
\hline \multicolumn{2}{|l}{} \\
\end{tabular}

Fig, 1 shows both the histogram of the normalized channel gain and the adjustment of lognormal density for data collected on August 16, 2014 around 06 AM under clear sky weather condition. The adjustment was obtained through a program developed using Matlab function lognfit which is based on the Maximum Likelihood method. 12,410 samples were collected using a digital oscilloscope.

Figure 1. Histogram of the normalized channel gain and lognormal fit.

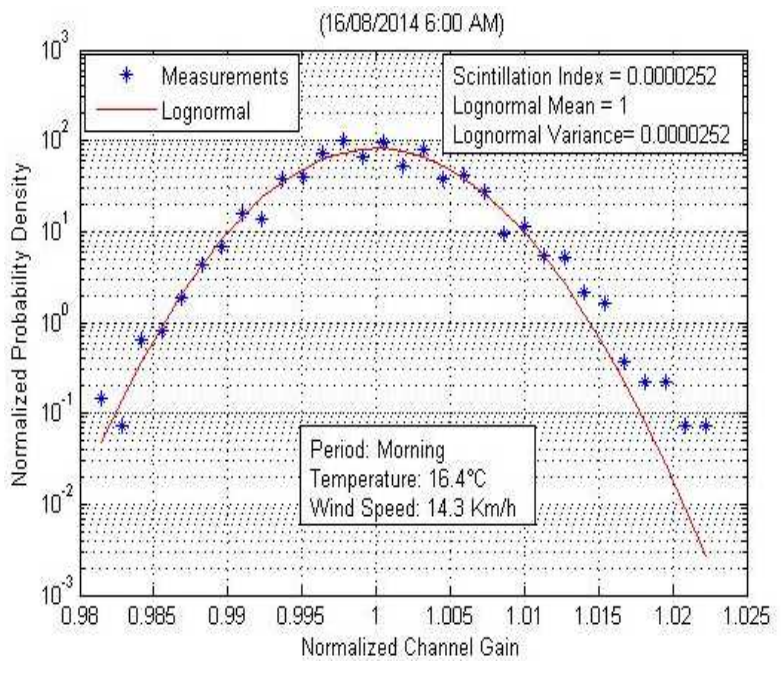

Conclusions

Even for very short link distances, significant scintillation index variations over a day were observed. The lognormal density fitted very well with the measurements. An expanded version of this article should appear in [1].

\section{Acknowledgement}

We would like to thank José Aparecido Cicarone for his support in deploying the link.

[1] C. J. R. Runge, M. V. da Silva and J. Portugheis, "Medidas de Canal para Comunicação Óptica pelo Espaço Livre" Proceedings of SBrT 2015, 1-4 September 2015, MG,Brasil, to appear. 